\title{
Smart Pedagogical Knowledge Management System
}

\author{
Meriyem Chergui ${ }^{1, *}$, Aziza Chakir ${ }^{2}$, Hajar Mansouri $^{1}$ \\ ${ }^{1}$ Department of Mathematics and Computer Sciences, Higher National School of Electricity and Mechanics, Hassan II University, \\ Casablanca, Morocco \\ ${ }^{2}$ Department of Economic Science and Management, Faculty of Economic and Social Legal Sciences, Hassan II University, \\ Casablanca, Morocco
}

Received August 18, 2020; Revised October 25, 2020; Accepted November 1, 2020

\begin{abstract}
Cite This Paper in the following Citation Styles
(a): [1] Meriyem Chergui, Aziza Chakir, Hajar Mansouri , "Smart Pedagogical Knowledge Management System," Universal Journal of Educational Research, Vol. 8, No. 12, pp. 6585-6597, 2020. DOI: 10.13189/ujer.2020.081223.
\end{abstract}

(b): Meriyem Chergui, Aziza Chakir, Hajar Mansouri (2020). Smart Pedagogical Knowledge Management System. Universal Journal of Educational Research, 8(12), 6585-6597. DOI: 10.13189/ujer.2020.081223.

Copyright $\mathrm{C} 2020$ by authors, all rights reserved. Authors agree that this article remains permanently open access under the terms of the Creative Commons Attribution License 4.0 International License

\begin{abstract}
The problem of knowledge in business was born several years ago. Indeed, new forms of work generate informal learning situations. This is how individuals develop their knowledge and skills. These situations are recognized by companies doing knowledge management. They encourage and make all to build communities of practice and knowledge exchange networks. This makes it possible to formalize the procedures, the good practices and the failures (feedback of experiences) thus to constitute sources of exploitable data. At the university, like any organization, each teacher has his/her own knowledge, his/her know-how, and he/she develops skills on his/her field of work in order to make that knowledge collected. This tacit or implicit teacher knowledge is shared so that each student can appropriate it and use it. However, depending on the nature of knowledge, and given the peculiarity of the pedagogical flow and its dependence on individuals (teacher), creating collective knowledge is not simple. During retirements, transfers, position change or any other academic life event, causing teacher displacement, knowledge may be lost. To deal with this problem, an empirical study of educational system perception of higher education in Morocco was carried out. Emphasis was placed on: pedagogical knowledge management, educational and e-learning platforms and overall student satisfaction. According to obtained results, we propose a smart education knowledge management system based on Artificial Intelligence to avoid loss of pedagogical knowledge and cover learning environment complexities and users' constraints;
\end{abstract}

Keywords Smart Education, Artificial Intelligence, Knowledge Management, Pedagogical Engineering,
e-Learning

\section{Introduction}

Knowledge Management (KM) has aroused much excitement in the recent years. KM can be considered as the process of organizing and leveraging firms' collective knowledge to achieve sustainability and to improve innovation [1], [2]. Indeed, business enterprises are not valued only at the net tangible assets recorded on their books. Evaluating an organization consists of considering in the most objective way its involvement and its intangible assets economic value.

Intangible asset can be defined as company knowledge, experience, database and even employees well-being. It represents everything that cannot be measured with financial tools in a company. One of intangible assets goals is related to value creation ability in the company (both in short term and over long term). It can be said that value creation is now based on knowledge. It is recognized as a strategic resource and a critical source of competitive advantage [3]. To stay competitive, a university like most organizations, should manage their intangible capital. Knowledge management in a university refers to the three main activities: teaching, research, and institutional management. In this article we will focus on teaching activity knowledge. In fact, teachers' retirement increases the need for sharing pedagogical objects and skills via pedagogical $\mathrm{KM}$ as a way to design, create and store teaching knowledge effectively. 
There are different techniques to develop and implement a knowledge management system. In [4] authors proposed an ontology-based KM system, which can assist engineers in sharing, searching, and managing knowledge.

In [5] authors use the Human Centered Distributed Information Methodology (HCDIM) in the design of a complex distributed knowledge management system for biomedical engineering domain in the mission control center at NASA. In [6] Meso and Smith propose an architecture which consists of functions, technology and knowledge. The technology should include e-task management, messaging etc. The functions utilize KM processes in using, finding, creating and packaging knowledge.

The term pedagogical knowledge management was first proposed by Akhterov in [7]. Authors in [8], [9], [10], [11] also discussed the management of pedagogical knowledge. They see knowledge management as a discipline that allows the use of available knowledge for the strategic development of an educational process. In [12] the term "pedagogical knowledge management" was used for the diagnosis of the knowledge management information system of teachers at the technical school.

The management of pedagogical knowledge is defined as $\mathrm{KM}$ of different pedagogical areas of a given educational process according to many quality aspects: teaching, classroom management, learning experiences and content evaluation. In literature, there are many application of pedagogical knowledge management, namely: lesson study process, lifelong learning, teachers' professional development, curriculum development and evidence based education. Every aspect was implemented by many KM solutions to improve learning systems and capitalize teachers and institutions feedbacks, as shown in references table below. Authors interested on details could look directly for references in the second column.

Table 1. Pedagogical knowledge management research applications

\begin{tabular}{|c|c|}
\hline Pedagogical area & References \\
\hline Lesson study process & {$[13],[14],[15],[16]$} \\
\hline Lifelong learning & {$[17],[18],[19],[20]$} \\
\hline $\begin{array}{c}\text { Teachers' professional } \\
\text { development and professional } \\
\text { qualifications promotion }\end{array}$ & {$[21],[22],[23],[24]$} \\
\hline Curriculum development & {$[25],[26],[27],[28],[29]$} \\
\hline Evidence Based Education & {$[30],[31],[32],[33],[34]$} \\
\hline
\end{tabular}

In this article, we deal with: educational design and curriculum development. And the main question to answer is how can we manage pedagogical knowledge to improve the curriculum and to design a smart education system with reusable learning objects? To answer this question, we carried out an empirical study of higher educational system in Morocco. After analysis of obtained results, we propose an intelligent architecture of a pedagogical knowledge management system. Indeed, artificial intelligence and expert systems can increase KM efficiency and provide intelligent services. The rest of the paper is organized as follows. In the next section, we will provide the literature review of both knowledge management, artificial intelligence and smart education. After, we will present the empirical study, we will analyze obtained results and we will present the proposed intelligent architecture that we will discuss before conclusion and work perspectives.

\section{Literature Review}

\section{Knowledge Management in higher education}

Knowledge management is the process of using tools and procedures to collect, organize, store, disseminate and share knowledge [35]. In addition, companies can set up a knowledge management approach to ensure the exploitation of intellectual property, as well as the capture and sharing experience feedback, since they have to adapt their environment to be able to withstand competition. In university like any organization, KM has a significant plus value in pedagogy research and organization. Universities had to make quick changes to progress. Knowledge become more and more complex and correlate to several factors: In the literature of KM in higher education several impacting factors had been identified namely organizational culture and structure, technology, promotion, and the linkages between industry and academia [36]. It focuses on three main components, creation, sharing and transfer of knowledge. Otherwise, universities are not fully and correctly committed to knowledge management. There is a lack of understanding and communication problems between different educative system stakeholders. Several authors have proposed solutions to KM problem at the university: Authors in [37] propose to focus on the institutional aspect. As for [38] KM is a research problem that must be resolved in every university according to its specificities. Some authors like [39] have focused on very particular aspects of pedagogical knowledge such as its individualistic nature and its different disciplines. The issue of inter-university knowledge sharing has also been raised by [40]. But, it should be noted that most of this research was done in countries with advanced educational systems (United Kingdom, India, Malaysia) where most of the eco-educational system is already in place and has reached an important maturity level. In this article we will deal with KM problem in a developing country university namely Morocco.

\section{a). Pedagogical Knowledge representation}

We distinguish different types of knowledge [41]. The first type is procedural knowledge representing how a problem is solved by indicating how to perform a task. The second is declarative knowledge that describes what is 
known about the problem (statements describing objects, concepts, etc.); there is also meta knowledge describing knowledge about knowledge definition. For example, what knowledge is adapted at a given moment to solve a given task; we can also find heuristic knowledge called surface knowledge which is an empirical knowledge acquired by an expert through his past experience, it serves to guide the reasoning. And at least structured knowledge that describes a mental model of the expert in structure form (concepts, sub-concepts, objects, etc.). In higher education context, many works used structured knowledge through ontologies to represent pedagogical knowledge namely: Mora-Arciniegas in [42] who used the semantic web to represent academic knowledge through ontologies, for better understanding and interoperability. Melgar in [43] have proposed an organizational memory architecture in higher education institutions. The proposed architecture allows the representation of knowledge for the semantic search of documents by adding semantics to documents by associating them with defined ontologies. In [44], authors indexed pedagogical objects for learners or teachers from different universities via semantic descriptors in distributed pedagogical warehouse. We can say that pedagogical knowledge is mainly structured and related to documents and ontological representation of the academic ecosystem gave good results.

\section{b). Knowledge management approaches for pedagogical use}

The most important KM step is knowledge modeling which is the process of intentional construction of experience, information and knowledge. Knowledge is basically modeled from documents and from actor reasoning. Several methods are used for knowledge modeling. These methods can be grouped into three types of approaches: bottom-up approach, top-down approach and mixed approach.

Bottom-Up or data-driven approach is based on a step of elicitation of expert knowledge (interviews, document analysis, task analysis, etc.) followed by a step of conceptualization. KOD (Knowledge Oriented Design) method [45] and Model-based and Incremental Knowledge Engineering (MIKE) method [46] are typical examples of this family.

Top-down approach: also known as a model-driven approach. The development of knowledge models in this approach consists in finding pre-existing generic models (in libraries, for example) and adapting them to the domain and application in question. Two sub-approaches can be distinguished in this family [47]: the select-and-modify approach such as KADS-I method and modeling-by-composition approach from library elements such as CommonKADS and MASK.

The Mixed approaches have been proposed in [48] and [49] to benefit from the advantages of different approaches. It's about building knowledge models by combining steps from the two previous approaches. In pedagogical KM,

The most used KM modeling method in higher education context is CommonKADS. It was used by Chayamarnie in [50] to design a university Credit Transfer System, by Bieger in [51] for task analysis in teaching cumulative learners' context, and also by Soratana in [52] to develop an e-tourism curriculum in Thailand.

\section{c). Memory of university system}

The term "corporate memory" refers to the knowledge and the know-how in action, mobilized by employees of a company to achieve business objectives. In the pedagogical context, authors in [53] adopt university corporate management memory in six steps: namely detection of business memory needs, its construction, its dissemination, the use and evaluation and we finish with memory maintenance and evolution. In [54] an approach to implement organizational memory of the university was proposed not only on pedagogical knowledge but also on other university knowledge (administrative, educational, intellectual capital). In this article, we will focus on teachers' knowledge for educational design and curriculum development.

\section{Artificial Intelligence for Knowledge Management}

Artificial Intelligence (AI) is architectural software paradigm which is used in $\mathrm{KM}$ domain, to assist user in an intelligent way so as to accomplish their work by saving the knowledge and suggesting it to suitable person. Thanks to autonomy and learning aspects of AI, many researchers have improved KM. Collaborative and distributed environment and social interaction can be handled by the AI to integrate knowledge searching complex function. Consequently, AI helps to ensure coordination and cooperation in KM platform. Many works were proposed to deal with activities related to KM. Some architectures have been designed for KM system development; others focus on a special domain with specific circumstances. The table below resumes works references using AI for KM [55]: 
Table 2. Knowledge Management research works using Artificial Intelligence

\begin{tabular}{|c|c|c|}
\hline Author & Focus & AI use for KM \\
\hline Gandon [56] & Project memory & $\begin{array}{l}\text { Intelligent agent to update knowledge through semantic web and } \\
\text { ontologies }\end{array}$ \\
\hline Tian [57] & Monitoring system & Multi agents monitoring system and service agents for patients \\
\hline Blanzieri [58] & Knowledge transfer & $\begin{array}{l}\text { System for implicit culture support encapsulate in communication } \\
\text { FIPA agent. }\end{array}$ \\
\hline Tacla [ 59] & Personal assistant & Automatic capture of desktop operations \\
\hline Laclavik [60] & Agent communication & Semantic web to relate KM to AI \\
\hline Dignum [61] & Knowledge transfer & $\begin{array}{l}\text { organization and knowledge needs analysis and matching with supply } \\
\text { according to user preferences. }\end{array}$ \\
\hline Soto $[62]$ & Knowledge reuse & Generic model for KM developing based on user preferences and \\
\hline Monticolo [63] & Project memory & Analysis and modeling of the project team process about KM. \\
\hline Bhat [64] & Log agent & Log model to record all KM agents activities (file activities) \\
\hline Ismail [65] & Knowledge acquisition & $\begin{array}{l}\text { AI seeking KM network to recognize expert knowledge sources and } \\
\text { its externalization. }\end{array}$ \\
\hline Rahman [66] & Service oriented & $\begin{array}{l}\text { AI for Knowledge circulation in public sector (dealing with timing } \\
\text { and service quality). }\end{array}$ \\
\hline Kamble [ 67] & Service oriented & $\begin{array}{c}\text { Agents communication to disseminate knowledge and improvethe } \\
\text { quality of organizational services }\end{array}$ \\
\hline
\end{tabular}

By comparing these approaches, we conclude that there is a large flexibility of AI use in KM and the choice of service-oriented approach, project memory or personal assistant depend principally on the KM domain and context. In the pedagogical context, many AI use for KM were done namely: Nica in [68] through a primitive empirical study deduce that intelligent knowledge management of smart learning environments allows to provide formal and informal education with the aim of building flexible learning environments. In [69] authors propose a framework for improving learning management systems usability via a conversational pedagogical agent and in [70], authors made a survey of artificial intelligence techniques employed for adaptive educational systems within e-learning platforms and deduce that artificial intelligence techniques develop and imitate the process of human reasoning and decision-making to design the learning-teaching framework

\section{Smart learning systems}

Smart learning is an innovative method currently used for employees training process as a smart training attitude [71]. In fact, recent e-learning standardization focuses on the reuse of learning material and functions [72]. It aims to put learners in interaction with courses and quizzes as resources according to a collection of activities. In order to identify learner's current level of understanding [73], online courses are mainly developing creativity, cognitive performance and emotional support [74]. One of the main goals of this new educative research discipline is to develop a new generation of intelligent tools for online learning using recommender systems.

Recommender system (RS) in e-learning is a system to assist learners in discovering convenient learning actions matching perfectly learners' profiles'. It is also able to define the best time, the best context and the best way to keep them motivated enough to complete their learning activities in an effective and efficient way. [75] presented many key features of smart education and smart competences. [76] focused on contemporary universities applications of smart ICT in education. In [78], authors propose a detailed study of universities and MOOC's role in smart education context. As for [79], authors introduced outcomes-based education as a part of the smart education paradigm.

In [80], instructional design and cognitive science take in consideration learning problems related to material, communication, and cognitive competence as resources matter. In [81], authors deal with the smart learning and smart e-learning problems. Many publications analyze different possible ways of implementing smart learning concept and design models and schemes of smart educational systems [82]. In [83] authors discuss conceptual model of ICT infrastructure of smart educational and e-learning systems as far as databases, standards, learning gadgets and equipment are concerned. [84] Analyzed smart education organizational aspects like smart learning strategies and educational path. Through these related works, we remark that smart education is implemented according to different aspects and users' expectations. The common point is the use of artificial intelligence and recommender system to make the educative system more flexible.

\section{Methodology}

In this article we deal with pedagogical knowledge in educational design and curriculum development aspects and we manage educational knowledge like business and 
technical knowledge of a company in a dynamic and changing environment. This vision corresponds to smart learning where the educational memory of the school or faculty represents the basis of an effective and efficient e-learning system.

By analyzing related works bellow, we find that there are three essential levels to design and implement in a smart education system, namely organization, information and communication technologies (ICT) and educational outcomes.

The question is how to design a smart learning system that deploys ICT efficiently in order to obtain a positive educational outcome? How to manage pedagogical knowledge ensuring its correct and effective use independently of the human factor? How to ensure the performance of a smart learning platform compared to international quality learning systems?

To answer these questions, we have developed an empirical study of perception intended for Moroccan higher education students. This study aims to understand students' needs, their learning problems and expectations.

This survey is carried out by researchers and business experts in order to propose a digital reform of the national higher education in line with the expectations of the national and international labor market. One of the main axes of this study is smart education and distance learning. In fact, we questioned 1174 higher education students of Hassan II University as shown in figure 1 and its attached engineering schools and faculties about many key actions namely: trainings contents satisfaction, tools and methodologies, training needs, learning performance, e-learning platforms expectations, communications and exchanges with teachers and professionals, and smart learning evaluation.

\section{Results}

In fact, $67.4 \%$ of questioned student are not satisfied with their training because of their theoretical aspect and luck of interactivity and practice. $78.9 \%$ of them think their learning system is neither efficient nor sufficient to master the elements and the modules of their training. In addition, $22 \%$ of students prefer distance education because of their social conditions and $44.2 \%$ no longer want to be present at school or faculty if smart education is completely adopted. Meanwhile, $18.3 \%$ of them already use Moocs and e-learning platforms to complete their pedagogical training.

While asking students about Moroccan university e-learning platform they need, $62.2 \%$ of them prefer custom education system, made by their teachers and continually compared to courses done by teachers and professionals all over the world. They opt for nominal authentication and training with multimedia support and documents as well. They suggest that the e-learning platform contains lessons by level of understanding (beginner, intermediate, advanced) (41.6\%). Those courses are animated by videos that show "how it is done" (step by step) $(43.6 \%)$. They also prefer practical research and innovation activities to be submitted for correction (27.9\%). Also, they think that discussions and exchanges are very important through smart education and e-learning platforms either with their own teachers $(26.9 \%)$, or with others teachers of the same specialty $(30.6 \%)$ and with professional trainers $(38.8 \%)$.
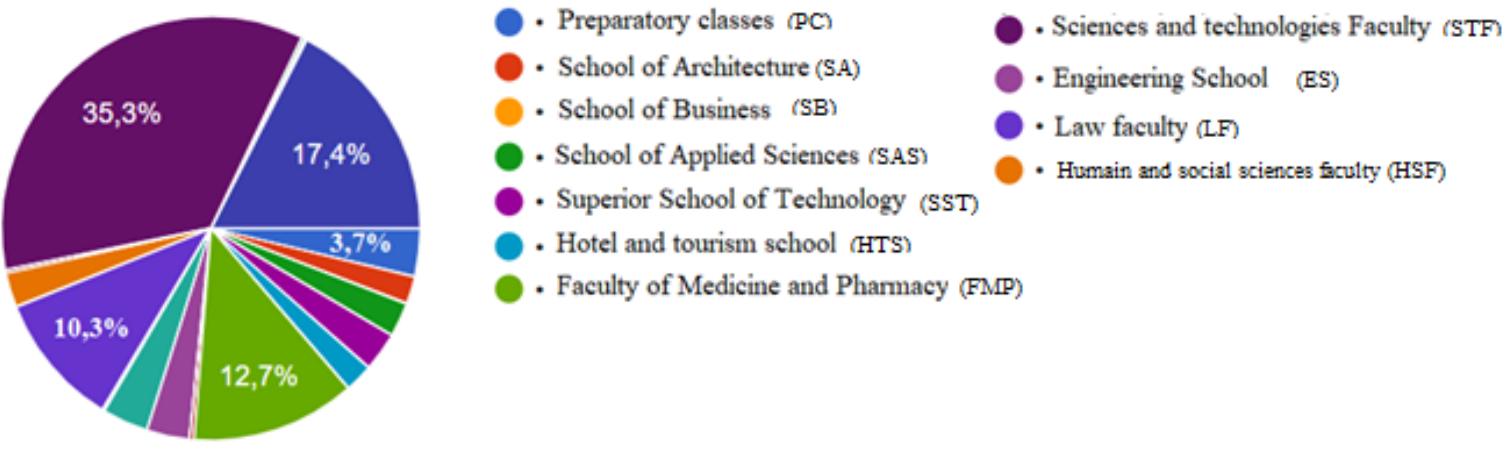

Figure 1. Questioned population 


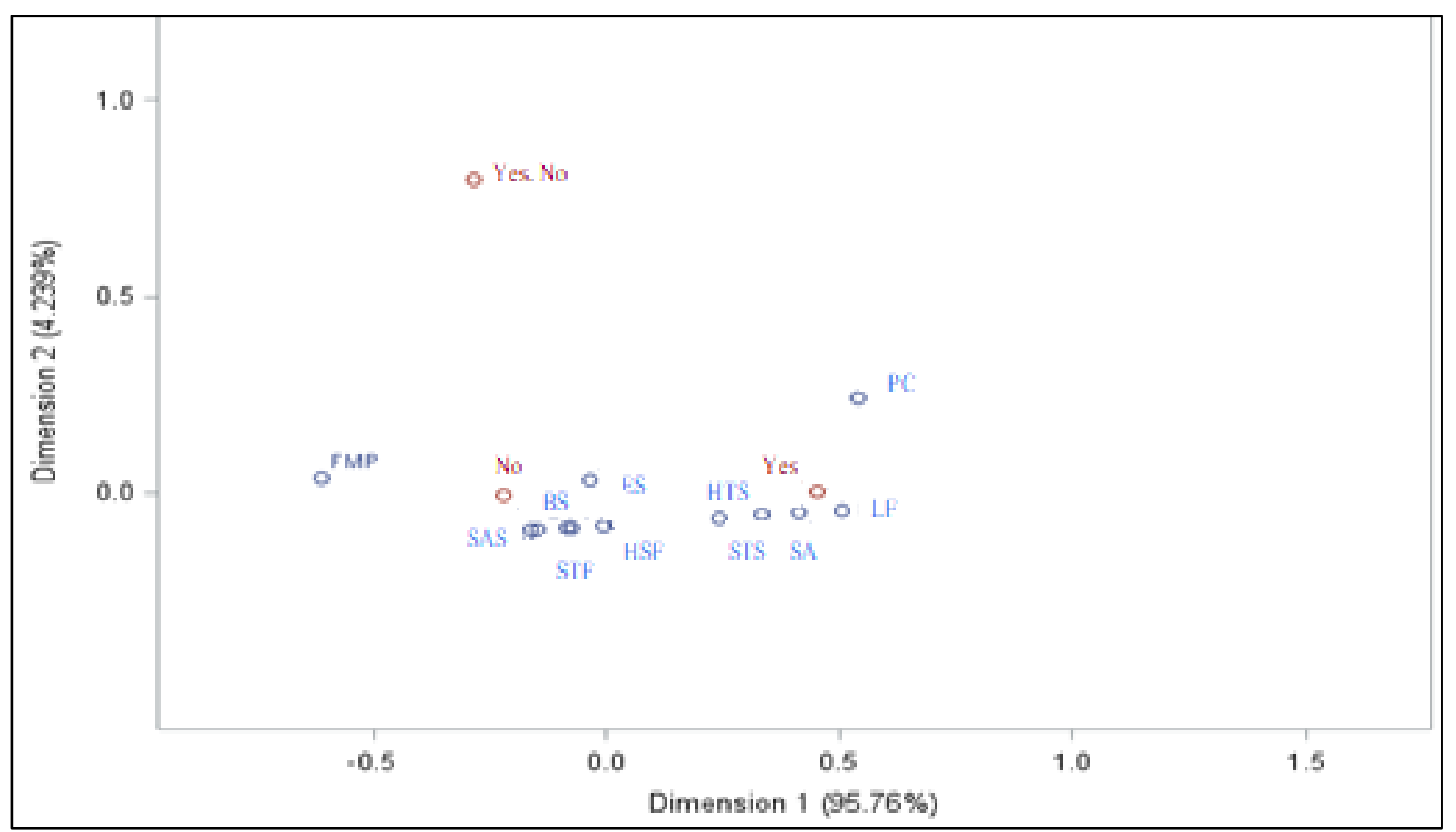

Figure 2. Faculty/ School correspondence analysis with training satisfaction

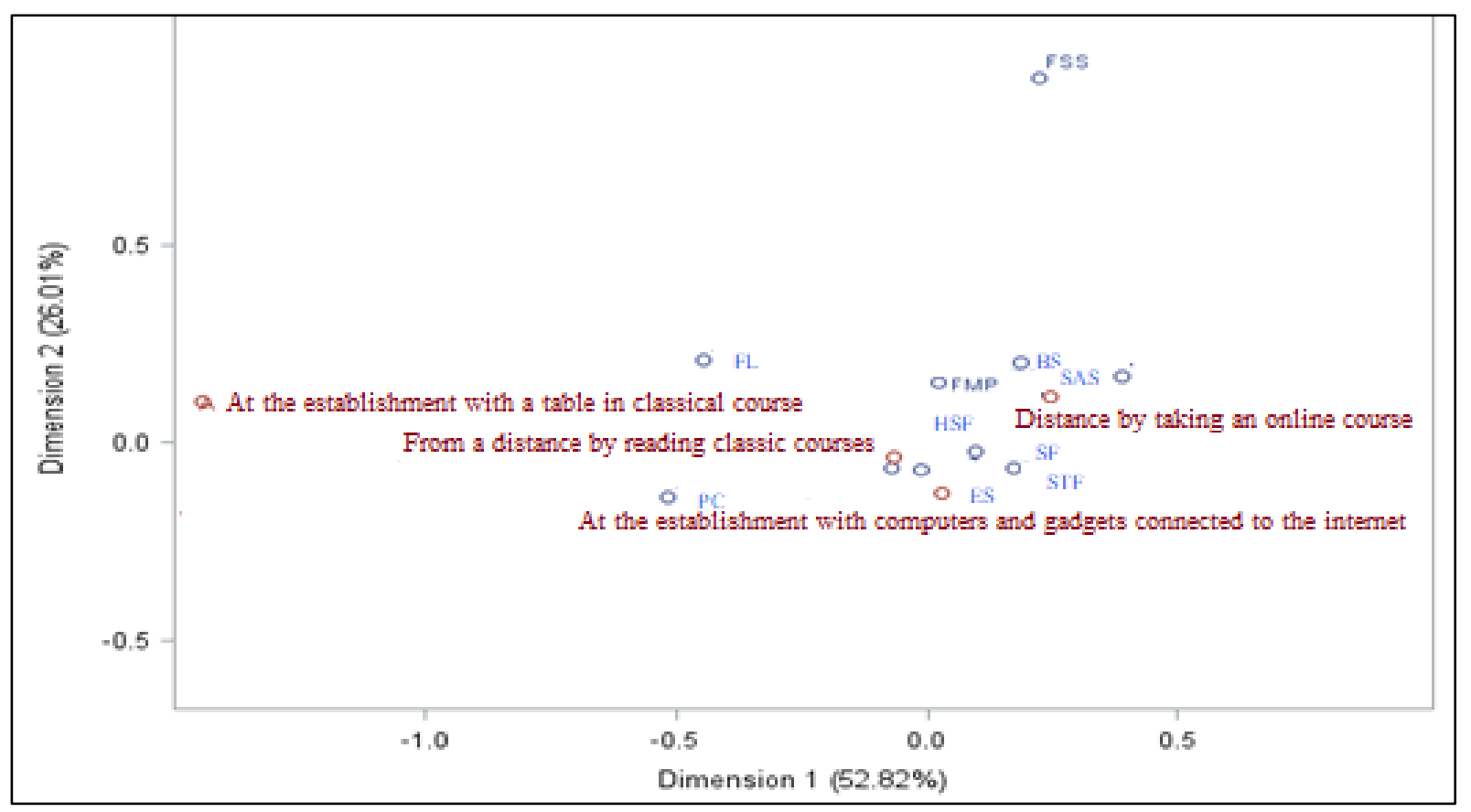

Figure 2. learning mode preferences

By carrying out a factorial analysis of the correspondences between students' satisfaction with their trainings and their school or faculty (Figure 2), we note that only 2 years' trainings give satisfaction contrary to engineering schools, medical and business schools or faculty as well as the science and technology faculties.

We also analyze their learning mode preferences (figure 3) and we remark that engineering schools, medical faculties, sciences and techniques faculties and technical trainings establishments prefer both distance learning with online courses and learning at school with connected gadgets. As for faculties of human and social sciences and legal sciences students, they prefer classical courses or distance learning via classical supports (books or e-books).

If we combine this observation to student satisfaction with their training, and we take into account courses nature and training methods variables, we can deduce that practical training students request the use of digital tools and information technology instead of blackboard lecture. Remote training is also a preferred option to complete 
training and to have more flexibility. This is understandable insofar as this type of training must be enriched by professional experience.

All the more, the fact that the majority of students of all types of training prefer courses designed by their own teachers emphasizes the necessity of an investment by teachers and establishments in curriculum design and information and communication technology.

On the other hand, while analyzing students learning mode decision as shown in figure 4, we remark that students from open access institutions prefer $100 \%$ distance education, as for students from limited access institutions, they prefer to attend depending on the course nature.

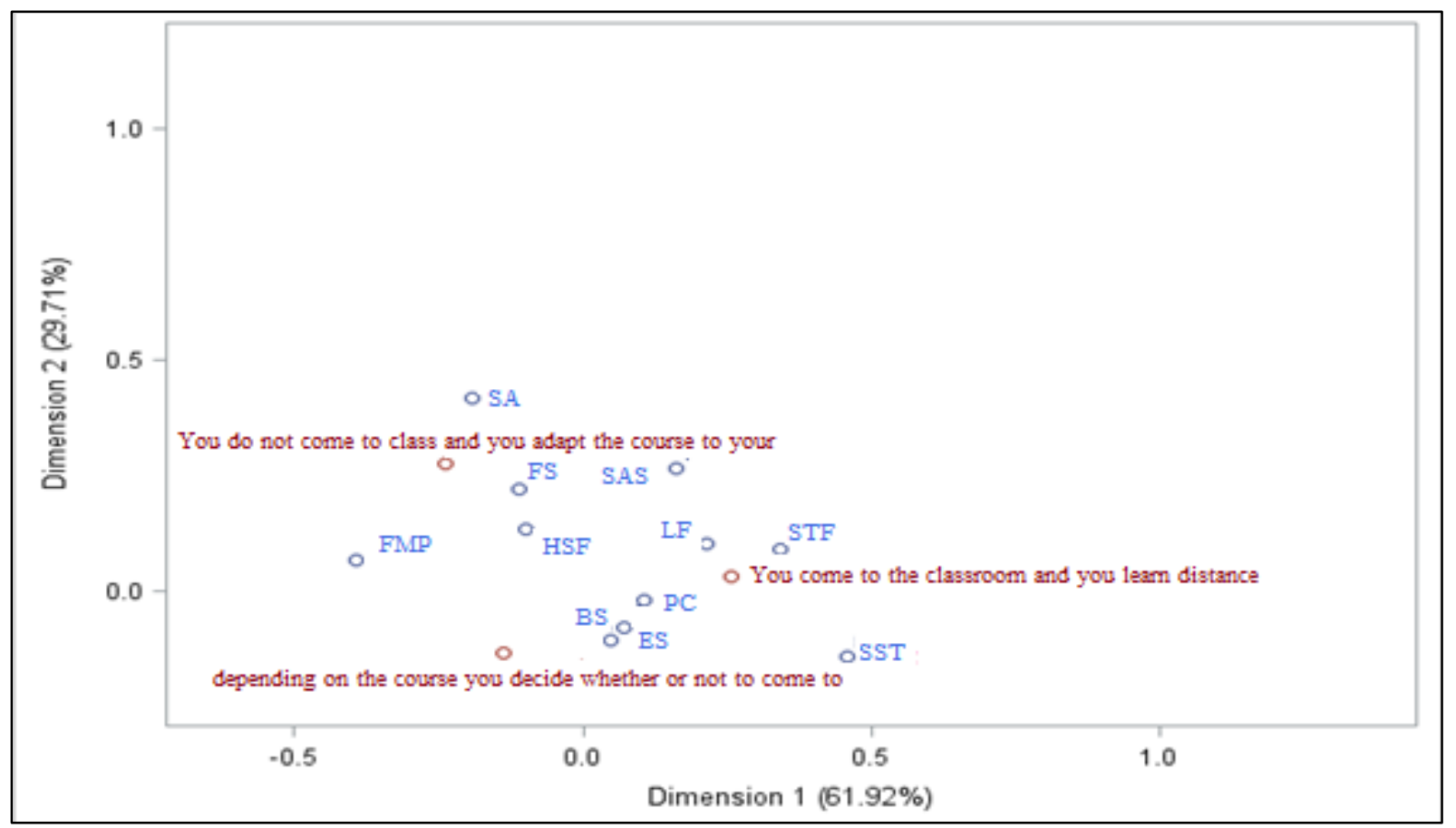

Figure 3. Students' learning mode decision

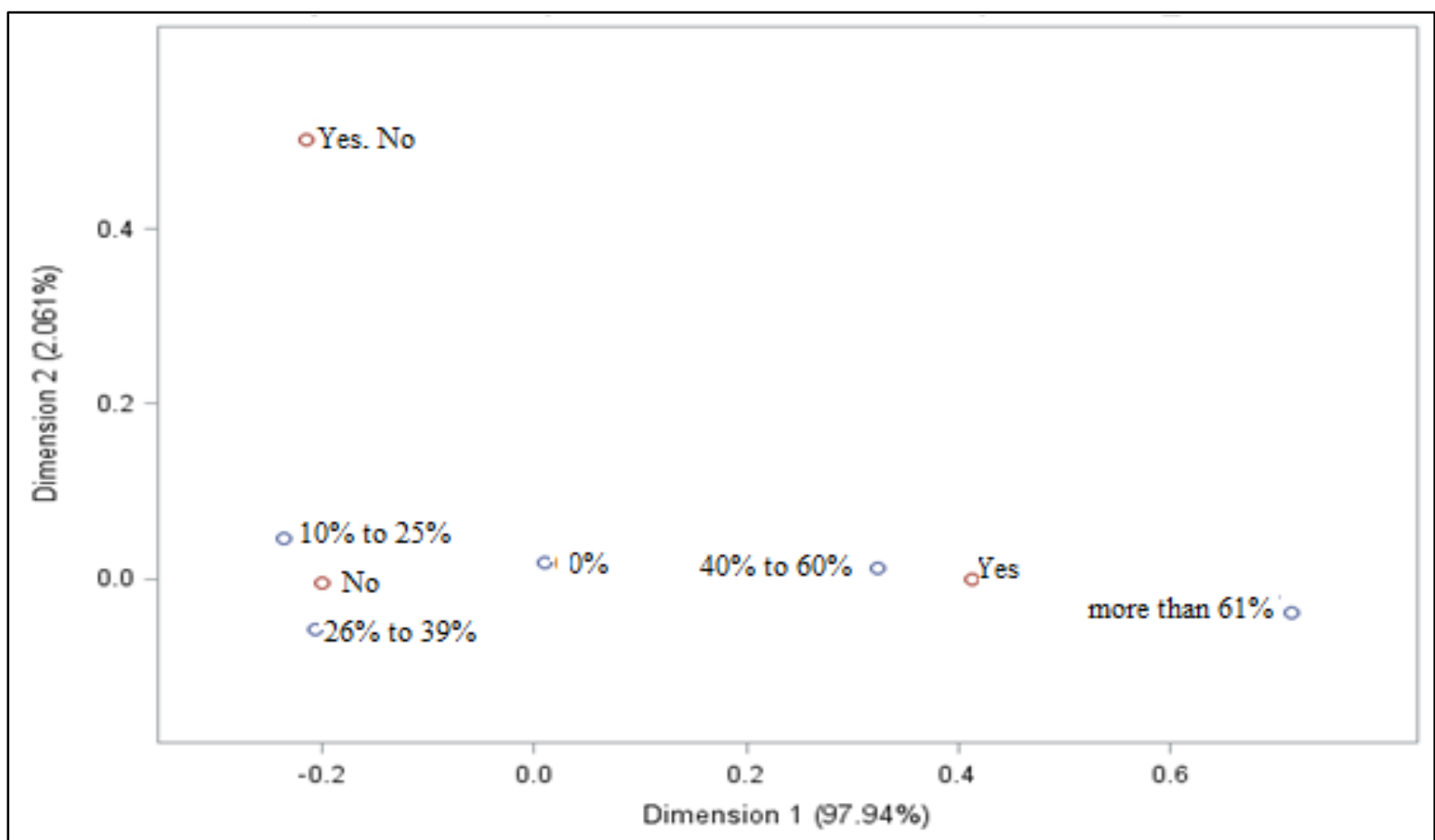

Figure 4. the correspondence between students satisfaction with their training and the interactivity of the course 
Another important parameter was evaluated. It is the correspondence between the satisfaction of students with their trainings and the interactivity of the course as shown in figure 5 . We found a strong correlation between the two variables. This can be explained by the lack of practical activities and dynamics in the course. Also, the standard, monotonous and repetitive aspect of these activities, if they exist, has an impact on students' concentration and involvement degree. This justifies the preference of limited access establishments students to be present if the course interests them and to follow distance training otherwise. This kind of trainings needs mainly practical and various activities to assimilate technical concepts and advanced skills.

One last point, student suggests that their courses and training should be all the time compared to other trainings worldwide (to avoid outdated trainings).

If we analyze all these results, we understand that the organizational dimension and the educational outcomes are two key expectations. Consequently, their efficient implementation is an up-to-date educational platform with new technologies, interactive content and well managed pedagogical knowledge.

These findings allow us to develop functional specifications of smart education model and efficient educational platform with high performance presented in the next section.

\section{Proposed Architecture}

The proposed architecture in figure 6 consolidates and manages the pedagogical knowledge of a teacher in one or more course or training he provides. The main objective is to preserve this knowledge which is lost by the departure of the teacher or his cessation, because the course is not only documents (slides and support) given to students. It is also explanations, examples and parallel activities (exercise, research works, mini projects, etc...). It is also the knowledge, the know-how and the competence of each teacher in his classroom and beyond the course. Indeed, it is a very recurrent pedagogical problem where the same course is given by several teachers with different levels of knowledge. This directly impacts the students learned skills, their motivation and their performance later in the socio-professional world. In [26] we proposed a pedagogical engineering meta-model of Moroccan university based on ICT. This model breaks down each course into a set of concepts and prerequisites governed by a generic pedagogical approach that can be detailed by several specific pedagogical approaches. This concerns every part of the course and every key concept. A specific approach has many implementation phases carried out by the main actors namely: student, teacher and professionals. Each actor performs one or more activities that are either educational or support. These activities deploy reusable learning objects and online services. We propose a smart learning KM system architecture (see figure 6) made of three subsystems, namely: Interactive system which contains teacher and student chatbots and which connect the platform to online courses through Http requests for annotated courses. Pedagogical processing system containing the pedagogical engineering engine to decompose a course to concepts, activities, approaches and learning objects according to [85] and KM system managing the pedagogical knowledge through courses as service and connected to the educational memory of a faculty or school as a knowledge base.

In fact, teacher creates or improves a course through a user interface answering chatbot questions to capitalize on his course knowledge. These questions are made from the engineering pedagogical model cited before [85]. Answers are sent to the pedagogical engineering unit in three levels: purpose definition, entities annotation and dialog evaluation to get more details. The hole system is service driven, so the http user requests are answered through course service. Pedagogical engineering unit launch tow algorithms: The first one is to create the course service if the course is new and starts the service if the course already exists. The second one handles the course service launched before, and confronts it to the pedagogical memory intelligent agent to evaluate it. This agent is a cognitive agent that analyzes the course service according to three scenarios, namely: courses without any corresponding concept (single scenario), course with concepts in common with other courses and courses already exist. Smart course agent is the intelligent unit that encompasses all the attributes, methods and services about a given course namely its concepts, approaches, activities and general knowledge. Agents communicate within ACL messages in a synchronal mode. Courses manager is the intelligent agent managing the smart course units. It instantiates, suspend and kill courses agents as it provides a yellow pages' service regarding existing courses in the platform and their status. Architecturally speaking, we have already implement an inter organizational workflow of intelligent agents in the same service logic in IT Governance context [86]. We also use a learning ontology as the domain ontology used by pedagogical processing system in order to understand teachers, students and online courses meta descriptions and annotations. It is a dynamic ontology enriched continually from online courses catalogues. Its main goal is to understand course service scenario described before. We will detail in a future article the used ontology to annotate courses, digital documents and pedagogical objects in this platform.

Learning agent can load concepts, approaches or activities of a course from courses catalogues. It can also create courses services from learning platforms with reusable learning object (Moodle for example). The pedagogical processing system enables fuzzy matching in 
entities definitions so as to make it easy to understand users' answers according to learning ontology. As for the student side, he discusses with chatbot to choose the best course he is looking for. Answers are sent to the courses research engine with recommender system to evaluate students' needs before giving him the course answer. The same understanding principal is used for both teachers and students to annotate a course. As for the educational knowledge base, it is considered as the organization memory where every course of every teacher in the high education school or faculty can be found. It is not only stored in a static way but we use semantic nets to represent the learning content for curriculum building. In fact, structured and unstructured documents are automatically annotated according to a five step semantic annotation pipeline in line with the used pedagogical ontology. The first step is text division and normalization where we divide the texts, filter it, and normalize it respecting the grammatical information. The second step is document index generation. The third is semantic extraction where we check whether an identified entity exists as an instance in the knowledge base and domain ontology, as well as for its synonyms and abbreviations. The fourth is entities grouping where an identified entity may have several references that must be grouped together and remove the ambiguity. And the last step is semantic annotation where metadata is associated with document entities through the annotation process.

\section{Discussion}

The aim of this solution is to implement a pedagogical engineering model [26] in a smart learning way. With the three subsystems described before, the smart learning KM system is able to manage the strategic dimension, the information and communication technologies dimension and the educational outcomes as well. In fact, students and teachers' involvement ensures learning system dynamic and avoids pedagogical knowledge management problems.

The pedagogical engineering engine of the processing system guarantees courses compliance and organization. It obliges teacher to follow a pedagogical model which breaks down a course into concepts and techniques. Every concept is linked to convenient educational approaches, activities and learning objects. This hierarchy ensures course's quality and makes it possible to assess educational outcomes.

The use of information and communication technologies is also favored in this system: teachers and students are connected to a web/mobile platform. At any time, teachers can design courses and students can follow them. KM system keeps track of every educational operation carried out, manages profiles and reusable educational objects as well.

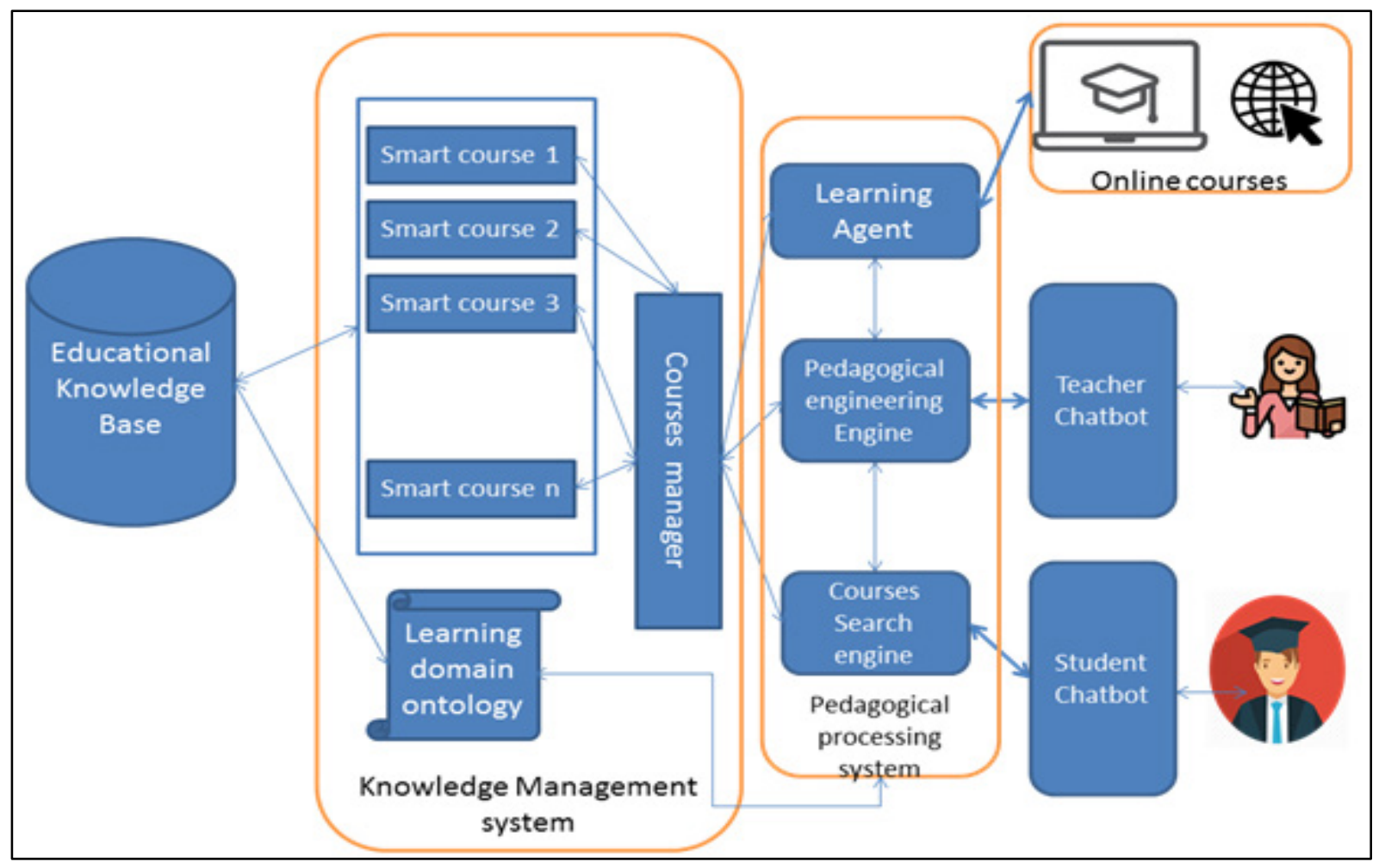

Figure 5. Smart Learning KMS 
The use of Artificial Intelligence to manage pedagogical knowledge is a technical and architectural solution to replace human assistance on several levels of the smart educational system. The use of chatbots to interact in real time with users and answer their questions is a major advantage of the solution. Through the platform, a teacher can design his course according to an educational engineering model. He can also modify it, and compare it to existing courses. The use of ontology to understand course concepts and their correspondence is a strong point of the solution able to identify the pedagogical entities and the relationships. In addition, the service driven aspect (course as service) of the platform ensures easy handling and updating. In COVID19 phase, the first version of the model was tested at the National Higher School of Electricity and Mechanics, Casablanca, Morocco for industrial and computer sciences engineering students, total of $\mathbf{1 0 0}$ students, 3 learning groups and $\mathbf{3}$ learning subjects: "Knowledge Management", "Software quality assurance" and "UML".

It gives great satisfaction among students as well as a major involvement of the teacher to implement the educational management system as shown in the figure 7 bellow:

\section{nsatisfied not satsfied}

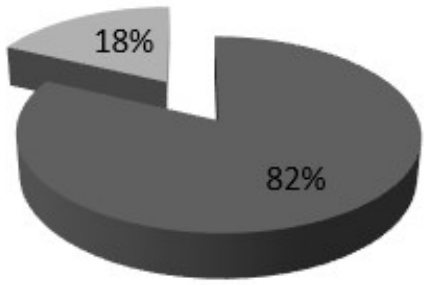

Figure 7. Students satisfaction test for the proposed model

The proposed pedagogical knowledge management system gives smart and easy use of educational computer systems to design every course in a guided manner following the educational meta-model. The designed course can also be used on-site or remotely according to student situation. One last question to answer is how general are results? And how these have to be of interest to everyone? We can say that e-learning configurations have succeeded in many cases, but those aimed at completely replacing teachers have failed. Hence the importance of pedagogical knowledge management on the one hand and the unavailability of the teacher in smart learning systems on the other hand (two criteria satisfied by the model proposed in this article). Otherwise, for new educational information systems, the institution has to make courses available for both students and teacher trough a pedagogical Knowledge Management system. Also, the real challenge is to describe the maximum learning situation in order to find the right combination of approaches for each situation as the pedagogical engineering engine do (two other criteria satisfied by the model proposed in this article).

\section{Conclusions}

In this article, we proposed a smart educational knowledge management system that enables the capitalization and consolidation of pedagogical knowledge in university context. After the state of the art of knowledge management and artificial intelligence in learning context, we presented an empirical study of perception intended for Moroccan higher education students to understand their pedagogical needs, problems and expectations from a smart learning system. To answer the main research question which was how can pedagogical knowledge be managed for reuse and improvement easily by teachers according to labor market needs and students' expectations? we proposed a smart educational KM architecture based on an educational engineering meta-model. Through this architecture, pedagogical knowledge is managed and improved by teachers according to a pedagogical engineering Meta model. This approach insures the quality and the update of contents in an intelligent way as well as the reuse of courses and pedagogical objects stored and annotated in the faculty educational knowledge base.

\section{REFERENCES}

[1] Zahra, S. A., Neubaum, D. O., \& Hayton, J. (2020). What do we know about knowledge integration: Fusing micro and macro-organizational perspectives? Academy of Management Annals, 14(1), 160-194

[2] Ramjeawon, P. V., \& Rowley, J. (2017). Knowledge management in higher education institutions: enablers and barriers in Mauritius. The Learning Organization.

[3] Guterres, J. X., Iriani, A., \& Purnomo, H. D. (2019). Knowledge Extraction on Reducing the Number of Students Using Explore, Elaborate and Execute Techniques. Khazanah Informatika: Jurnal Ilmu Komputer dan Informatika, 5(2), 146-157

[4] Srisa-an, C., \& Denphaisarn, N. (2016). An ontology based knowledge management for a user preference of e-learning system.

[5] Dalkir, K. (2017). Knowledge management in theory and practice. MIT press.

[6] Sun, J. H., \& Yoon, J. H. (2016). The Conceptual Study of Knowledge Adoption based on Resource and Institutionalization Theory for Organizational Knowledge Creation Applied to Knowledge Management Systems. Management \& Information Systems Review, 35(2), 
$119-136$

[7] Akhterov, A., Borisevich, V., Lezina, O., Minina, O., \& Fedorov, I. (2010, September). Pedagogical knowledge management system in a department on technical university. In Proceedings of the Joint International IGIP-SEFI Annual Conference (pp. 19-22).

[8] Hwang, G. J., \& Xie, H. (2018). Review and trend analysis of knowledge management and e-learning research. Knowledge Management \& E-Learning: An International Journal, 10(4), 371-374.

[9] Supermane, S., \& Zainal, A. (2020). Assessing Knowledge Management in Teacher Education. International Journal of Instruction, Technology, and Social Sciences, 1(2), 36-40.

[10] Xu, J., Hou, Q., Niu, C., Wang, Y., \& Xie, Y. (2018). Process optimization of the University-Industry-Research collaborative innovation from the perspective of knowledge management. Cognitive Systems Research, 52, 995-1003.

[11] Wang, X., Xi, Y., Xie, J., \& Zhao, Y. (2017). Organizational unlearning and knowledge transfer in cross-border M\&A: the roles of routine and knowledge compatibility. Journal of Knowledge Management.

[12] Lezina, O. V., \& Akhterov, A. V. (2013, September). Designing of the information component of pedagogical knowledge management system in a chair of technical university. In 2013 International Conference on Interactive Collaborative Learning (ICL) (pp. 544-546). IEEE.

[13] Cheng, E. C. (2019). Reconceptualising Lesson Study as Knowledge Management. In Successful Transposition of Lesson Study (pp. 17-28). Springer, Singapore.

[14] Cheng, E. C. (2018). Successful transposition of lesson study: a knowledge management perspective. Springer.

[15] Clivaz, S. (2018). Lesson study as a fundamental situation for the knowledge of teaching. International Journal for Lesson and Learning Studies.

[16] Akbari, N., Ayati, M., Zare, M. A., \& Pourshafei, H. (2018). The effect of knowledge management process on lifelong learning literacy of foreign language teachers in secondary schools.

[17] Kasemsap, K. (2016). The roles of lifelong learning and knowledge management in global higher education. In Impact of economic crisis on education and the next-generation workforce (pp. 71-100). IGI Global.

[18] Ivanova, V., Toskova, A., Stoyanova-Doycheva, A., Stoyanov, S., \& Veselinova, M. (2017, September). Lifelong learning in Virtual education space with intelligent assistants. In Proceedings of the 8th Balkan Conference in Informatics (pp. 1-6)

[19] Qalehsari, M. Q., Khaghanizadeh, M., \& Ebadi, A. (2017). Lifelong learning strategies in nursing: A systematic review. Electronic physician, 9(10), 5541.

[20] Pattnayak, J. (2020). Innovative Method of Lifelong Learning in the Digital Environment. In Digital Innovations for Customer Engagement, Management, and Organizational Improvement (pp. 221-236). IGI Global.

[21] Olaisen, J., \& Revang, O. (2017). Working smarter and greener: Collaborative knowledge sharing in virtual global project teams. International Journal of Information Management, 37(1), 1441-1448.

[22] Millar, C. C., Chen, S., \& Waller, L. (2017). Leadership, knowledge and people in knowledge-intensive organisations: implications for HRM theory and practice.

[23] Kandiah, D. A. (2017). Clinical reasoning and knowledge management in final year medical students: the role of Student-led Grand Rounds. Advances in Medical Education and Practice, 8, 683.

[24] Chen, C. C. (2018). Facilitation of teachers' professional development through principals' instructional supervision and teachers' knowledge-management behaviors. Contemporary Pedagogies in Teacher Education and Development, 51.

[25] Tarnekar, S. (2017). Application of knowledge management to curriculum development processes. Journal of Commerce and Management Thought, 8(3), 383.

[26] Tjong, Y., Warnars, H. L. H. S., \& Adi, S. (2016, November). Designing Knowledge Management model for curriculum development process: A case study in Bina Nusantara University. In 2016 International Conference on Information Management and Technology (ICIMTech) (pp. 17-22). IEEE.

[27] CHENG, C. K. E. (2017). Developing personal knowledge management training curriculum guide and resources.

[28] Tsabedze, V. (2019, December). Strategies for Developing an Open Distance e-Learning Curriculum for an Information and Knowledge Management Programme: A Case of the Kingdom of Eswatini. In ICICKM 2019 16th International Conference on Intellectual Capital Knowledge Management \& Organisational Learning (p. 356). Academic Conferences and publishing limited.

[29] Sung, S., \& Kaewkongka, P. (2020). Knowledge management for development of undergraduate curriculum in general education. Actual Economy: local solutions for global challenges, 142-150.

[30] Al-Jedaiah, M. (2020). Knowledge management and e-learning effectiveness: Empirical evidence from Jordanian Higher Education Institutions. International Journal of Emerging Technologies in Learning (iJET), 15(5), 50-62.

[31] OGATA, H., MAJUMDAR, R., AKÇAPINAR, G., HASNINE, M. N., \& Flanagan, B. (2018, November). Beyond Learning Analytics: Framework for Technology-Enhanced Evidence-Based Education and Learning. In 26th International Conference on Computers in Education Workshop Proceedings (pp. 493-496). Asia-Pacific Society for Computers in Education (APSCE).

[32] Escueta, M., Quan, V., Nickow, A. J., \& Oreopoulos, P. (2017). Education technology: An evidence-based review (No. w23744). National Bureau of Economic Research.

[33] OGATA, H., MAJUMDAR, R., AKCAPINAR, G., HASNINE, M. N., \& Flanagan, B. (2018, November). Beyond Learning Analytics: Framework for Technology-Enhanced Evidence-Based Education and Learning. In 26th International Conference on Computers in Education Workshop Proceedings (pp. 493-496). Asia-Pacific Society for Computers in Education (APSCE). 
[34] Fidalgo-Blanco, Á., Sein-Echaluce, M. L., \& García-Peñalvo, F. J. (2017, October). APFT: active peer-based flip teaching. In Proceedings of the 5th International Conference on Technological Ecosystems for Enhancing Multiculturality (pp. 1-7).

[35] Cerchione, R., \& Esposito, E. (2017). Using knowledge management systems: A taxonomy of SME strategies. International Journal of Information Management, 37(1), $1551-1562$

[36] Elrehail, H., Emeagwali, O. L., Alsaad, A., \& Alzghoul, A. (2018). The impact of transformational and authentic leadership on innovation in higher education: the contingent role of knowledge sharing. Telematics and Informatics, 35(1), 55-67.

[37] Scarso, E. (2017). Corporate universities as knowledge management tools. VINE Journal of Information and Knowledge Management Systems.

[38] Sharma, M. K., \& Kaur, M. (2016). Knowledge management in higher education institutions. IRA-International Journal of Management \& Social Sciences, 4(3), 548-555.

[39] Saadat, V., \& Saadat, Z. (2016). Organizational learning as a key role of organizational success. Procedia-Social and Behavioral Sciences, 230, 219-225.

[40] Cheng, E. C., Wu, S. W., \& Hu, J. (2017). Knowledge management implementation in the school context: case studies on knowledge leadership, storytelling, and taxonomy. Educational Research for Policy and Practice, 16(2), 177-188.

[41] Chergui, M., \& Chakir, A. (2020). Jestr r. Journal of Engineering Science and Technology Review, 13(5), 67-76.

[42] Mora-Arciniegas, M. B., Piedra, N., \& Tenesaca-Luna, G. A. (2017, November). Semantic representation of teaching planning, pilot experience at UTPL. In 2017 IEEE 37th Central America and Panama Convention (CONCAPAN XXXVII) (pp. 1-6). IEEE.

[43] Melgar, A., \& Quilca, A. (2016, June). An architecture for organizational memory systems in institutions of higher education. In 2016 11th Iberian Conference on Information Systems and Technologies (CISTI) (pp. 1-6). IEEE.

[44] Korchi, A., El Idrissi, N. E. A., Messaoudi, F., \& Dardor, M. (2020). Ontology for distributed architecture of pedagogical warehouse in the field of machine learning. Education and Information Technologies, 1-12.

[45] Dalkir, K. (2017). Knowledge management in theory and practice. MIT press.

[46] Sun, J. H., \& Yoon, J. H. (2016). The Conceptual Study of Knowledge Adoption based on Resource and Institutionalization Theory for Organizational Knowledge Creation Applied to Knowledge Management Systems. Management \& Information Systems Review, 35(2), 119-136.

[47] Chakir, A., Chergui, M., \& Andry, J. F. (2020). A smart updater it governance platform based on artificial intelligence. risk, 8,9 .

[48] Pedro, E., Leitao, J., \& Alves, H. (2018). Back to the future of intellectual capital research: a systematic literature review. Management Decision.
[49] Megder, E., Cherkaoui, C., \& Mammass, D. (2017, March). Apport de la théorie de l'activité et des outils collaboratifs à la gestion des connaissances. In Proceedings of the 2nd international Conference on Big Data, Cloud and Applications (pp. 1-6)

[50] Bhiriyawanit, C., \& Bouras, A. (2019). A knowledge management approach to compare and develop the ASEAN University Credit Transfer System in Thailand.

[51] Bieger, J. E., \& Thórisson, K. R. (2018, August). Task analysis for teaching cumulative learners. In International Conference on Artificial General Intelligence (pp. 21-31). Springer, Cham.

[52] Soratana, K., Landis, A. E., Jing, F., \& Suto, H. A Knowledge Supply Chain for the ICT-Enhanced Tourism Education. In Supply Chain Management of Tourism Towards Sustainability (pp. 31-41). Springer, Cham.

[53] Chen, H., Nunes, J. M. B., Ragsdell, G., \& An, X. (2019). Somatic and cultural knowledge: drivers of a habitus-driven model of tacit knowledge acquisition. Journal of Documentation.

[54] Laoufi, A., Mouhim, S., Megder, E. H., Cherkaoui, C., \& Mammass, D. (2011). Using knowledge management in higher education: research challenges and opportunities. Journal of Theoretical and Applied Information Technology, 31(2), 100-108.

[55] Ali, S. S., \& Ismail, S. (2018, July). Adoption of Agent-mediated Knowledge Management to Increase Social Presence in Digital Community. In Proc. of the Knowledge Management International Conference (KMICe) 2018

[56] Gandon, F. (2002). Distributed Artificial Intelligence and Knowledge Management: ontologies and multi-agent systems for a corporate semantic web (Doctoral dissertation)

[57] Tian, J., \& Tianfield, H. (2003, September). A Multi-agent Approach to the Design of an E-medicine System. In German Conference on Multiagent System Technologies (pp. 85-94). Springer, Berlin, Heidelberg.

[58] Blanzieri, E., Giorgini, P., Giunchiglia, F., \& Zanoni, C. (2003, March). Implicit culture-based personal agents for knowledge management. In International Symposium on Agent-Mediated Knowledge Management (pp. 245-261). Springer, Berlin, Heidelberg.

[59] Tacla, C. A., \& Barthès, J. P. (2003). A multi-agent system for acquiring and sharing lessons learned. Computers in Industry, 52(1), 5-16.

[60] Suwardi, I. S., \& Surendro, K. (2014, November). An overview of multi agent system approach in knowledge management model. In 2014 International Conference on Information Technology Systems and Innovation (ICITSI) (pp. 62-69). IEEE.

[61] Dignum, V. (2005, October). An overview of agents in knowledge management. In International Conference on Applications of Declarative Programming and Knowledge Management (pp. 175-189). Springer, Berlin, Heidelberg.

[62] Soto, J. P., Vizcaíno, A., \& Piattini, M. (2017). Fostering Knowledge Reuse in Communities of Practice by Using a Trust Model and Agents. International Journal of 
Information Technology \& Decision Making, 16(05), 1409-1439.

[63] Monticolo, D., \& Lahoud, I. (2020). An Agent Approach to Manage Heterogeneous and Distributed Knowledge. International Journal of Knowledge-Based Organizations (IJKBO), 10(1), 27-48.

[64] Bhat, S., \& Wahid, A. (2012). Log Agent for Knowledge Management Based on Multi-Agent System. International Journal of Emerging Technology and Advanced Engineering, 2(7).

[65] Tangaraja, G., Rasdi, R. M., Samah, B. A., \& Ismail, M. (2016). Knowledge sharing is knowledge transfer: a misconception in the literature. Journal of Knowledge Management.

[66] Rahman, S. A., Bhardwaj, A., Pathak, M., \& Rathore, S. S. (2011). Introduction of knowledge management architecture using multi agent. International Journal of Computer Science \& Information Technology, 3(6), 229.

[67] Kamble, D. R. (2013). Architectural review on multi agent knowledge management. International Journal Of Scientific and Technology Research, 2(6).

[68] Nica, E. (2017). Techno-pedagogy knowledge in smart learning environments. Economics, Management, and Financial Markets, 12(1), 75-81.

[69] Odhiambo, B. A., Okeyo, G., \& Cheruiyot, W. (2017). Framework for improving usability of learning management systems by integrating pedagogical agent. International Journal of Computer Applications, 166(8), 7-16.

[70] Chergui, M., Chakir, A., Medromi, H., \& Radoui, M. (2016, May). A New Approach for Modeling Strategic IT Governance Workflow. In International Symposium on Ubiquitous Networking (pp. 285-298). Springer, Singapore.

[71] Mittal, N., Chaudhary, M., \& Alavi, S. (2020). An Evaluative Framework for the Most Suitable Theory of Mobile Learning. In Managing Social Media Practices in the Digital Economy (pp. 1-24). IGI Global.

[72] Shafrir, U. (2020). Meaning Equivalence Reusable Learning Objects (MERLO) Access to Knowledge in Early Digital Era and Development of Pedagogy for Conceptual Thinking. In Pedagogy for Conceptual Thinking and Meaning Equivalence: Emerging Research and Opportunities (pp. 22-53). IGI Global.

[73] Raghunathan, V. S., Sathya, A., \& Devi, N. (2017). Design and analysis of agent architecture for dashboard platform domain services. Advances in Natural and Applied Sciences, $11(8), 424-433$

[74] Mueller, S. (2020). The mature learner: understanding entrepreneurial learning processes of university students from a social constructivist perspective (Doctoral dissertation).
[75] Cui, Y., Zhang, H., \& Liu, S. (2019, December). Research on Teacher Teaching Competence (TTC) Model Under Smart Education. In 2019 International Joint Conference on Information, Media and Engineering (IJCIME) (pp. 38-41). IEEE.

[76] Xi, J., \& He, W. (2017, December). Research on Innovation and Practice Ability of Computer Major Students in Contemporary Universities. In 4th International Conference on Education, Management, Arts, Economics and Social Science (ICEMAESS 2017). Atlantis Press

[77] Cabral, P., Paz, J., \& Teixeira, A. (2020). The Impact of a Research-Based Institutional Strategy for Opening up Educational Practices: The Case of the MOOC-Maker Project. In Project and Design Literacy as Cornerstones of Smart Education (pp. 53-65). Springer, Singapore.

[78] Das, D. K., \& Mishra, B. (2018). Exploring the Complementarity of Problem Based Learning with Outcomes Based Education in Engineering Education: A case study in South Africa. In 7 th International Research Symposium on PBL (p. 297).

[79] Verschaffel, L., Van Dooren, W., \& Star, J. (2017). Applying cognitive psychology based instructional design principles in mathematics teaching and learning: introduction. ZDM, 49(4), 491-496.

[80] Truong, H. M. (2016). Integrating learning styles and adaptive e-learning system: Current developments, problems and opportunities. Computers in human behavior, 55, 1185-1193.

[81] Gros, B. (2016). The design of smart educational environments. Smart Learning Environments, 3(1), 15.

[82] Vlacic, L. (2018). Smart Education and E-learning 2017 (Vol. 99). V. L. Uskov, R. J. Howlett, \& L. C. Jain (Eds.). Springer.

[83] Daniela, L., Chui, K. T., Visvizi, A., \& Lytras, M. D. (2019). On the Way to Smart Education and Urban Society. In Knowledge-Intensive Economies and Opportunities for Social, Organizational, and Technological Growth (pp. 1-11). IGI Global.

[84] Uskov, V. L., Bakken, J. P., Karri, S., Uskov, A. V., Heinemann, C., \& Rachakonda, R. (2017, June). Smart university: conceptual modeling and systems' design. In International Conference on Smart Education and Smart E-Learning (pp. 49-86). Springer, Cham

[85] M. Chergui, A. Tahiri, A. Chakir, H. Mansouri "Towards a new educational engineering model for Moroccan university based on ICT", International Journal of Engineering Pedagogy (iJEP), Vol 10, N³(2020) May 2020.

[86] Chergui, M., Chakir, A., Medromi, H., \& Radoui, M. (2016, May). A New Approach for Modeling Strategic IT Governance Workflow. In International Symposium on Ubiquitous Networking (pp. 285-298). Springer, Singapore. 